\title{
Utilidades e limitações do uso de diretrizes no tratamento da depressão
}

A Revista Brasileira de Psiquiatria apresenta, neste número, as Diretrizes para o Tratamento da Depressão, dentro do programa de Diretrizes estabelecido pela Associação Médica Brasileira (AMB). Este documento foi elaborado por colegas (Marcelo Pio de Almeida Fleck, Beny Lafer, Everton Botelho Sougey, José Alberto Del Porto, Marco Antônio Brasil e Mário Francisco Juruena) identificados com o diagnóstico e tratamento de transtornos de humor em diferentes instituições e localidades (Porto Alegre, São Paulo, Rio de Janeiro e Recife). A metodologia empregada foi o exame de diretrizes desenvolvidas em outros países, assim como artigos de revisão sistemática, ensaios clínicos randomizados e, em último caso, estudos não controlados ou recomendação de grupo de experts.

O estabelecimento de um consenso brasileiro é necessário. Infelizmente, ele se baseia em estudos realizados majoritariamente no exterior, já que a produção científica nacional, ainda que crescente, é pequena, o que fica evidente pelo fato de somente três dos 106 trabalhos citados na bibliografia envolverem brasileiros. Em relação a algumas informações, os dados internacionais não são transponíveis para a nossa realidade, como é o caso dos aspectos farmacoeconômicos. Nesse ponto, apesar de não ser o seu propósito, este documento é precioso em apontar áreas em que a pesquisa brasileira deve avançar.

Esta iniciativa da AMB deve ser louvada, porque o uso de diretrizes traz, de modo geral, diversas vantagens: pode melhorar o julgamento clínico e o reconhecimento do transtorno, com possível influência favorável sobre o desfecho; proporciona suporte para a decisão clínica; tende a aproximar o clínico da medicina baseada em evidências; e ainda constitui-se em fonte de educação e pesquisa.

Entretanto, existem limitações no uso de diretrizes. Algumas são apontadas por McIntyre: ${ }^{1}$ falta de implementação - os médicos geralmente não usam as diretrizes no trabalho clínico do dia-a-dia; brechas nas pesquisas - tratamento de longoprazo, eficácia das psicoterapias, condições resistentes aos tratamentos, pacientes com diagnósticos múltiplos, etc; abordagem reducionista - as diretrizes podem ser vistas pelo clínico como "receitas de bolo" e não incluir todos os métodos ou cuidados adequados disponíveis; aspectos culturais, como conhecimento limitado do impacto dos aspectos culturais sobre as decisões terapêuticas; risco de processos - a não-adesão dos médicos às recomendações das diretrizes aprovadas por associações nacionais poderia ser utilizada em processos por não se seguirem os cuidados padronizados; e disponibilidade limitada de recursos, resultando na impossibilidade de utilização de padrões ótimos de cuidados.

Outra limitação que poderia ser apontada é o fato de algumas drogas serem mais pesquisadas do que outras, em função de interesses econômicos (drogas protegidas por patente, por exemplo), e da maior parte dos ensaios clínicos serem realizados pela indústria farmacêutica e não por equipes independentes, fatos que seriam importantes vieses na interpretação desses dados.

Assim, algumas considerações de cautela se fazem necessárias quanto ao uso de diretrizes pelo clínico geral, quando se trata de diagnosticar e tratar transtornos mentais, a exemplo dos transtornos de ansiedade e, particularmente, da depressão. Nesse último caso, um grande ensaio denominado The Hampshire Depression Project, ${ }^{2}$ envolvendo 55 centros de atenção primária, após treinamento dos médicos no reconhecimento da depressão em 26 deles (grupo experimental), não melhorou nem o reconhecimento dela, nem a recuperação dos 4.192 pacientes selecionados e previamente diagnosticados como deprimidos, através de uma escala de depressão e ansiedade. A sensibilidade dos clínicos gerais aos sintomas depressivos foi de $39 \%$, contra $36 \%$ no grupo controle (odds ratio $=1,2$; intervalo de confiança de $95 \%=0,88-1,61$ ). Se considerarmos que as diretrizes aqui apresentadas serão apenas lidas pelos clínicos, sem qualquer treinamento, é provável que os resultados sejam ainda menos promissores.

Uma revisão de 45 diretrizes clínicas sobre depressão, elaboradas no Reino Unido, ${ }^{3}$ faz, essencialmente, as mesmas recomendações: que os clínicos identifiquem casos de depressão maior - diagnóstico que prediz maior taxa de respostas aos antidepressivos -, e que o tratamento seja feito em dose adequada, por tempo adequado, esses últimos equivalendo a pelo menos $125 \mathrm{mg}$ de amitriptilina, por pelo menos quatro meses após a recuperação.

Como as diretrizes aqui propostas se destinam não somente aos psiquiatras, mas também aos clínicos em geral, coube re- 
forçar a questão do reconhecimento do diagnóstico do transtorno de humor bipolar. O grande número de pessoas utilizando antidepressivos sem o reconhecimento de elementos sugestivos desse transtorno, tem acarretado piora do quadro clínico e do prognóstico desses pacientes. Assim, todo programa que popularize o uso de antidepressivos deve ser acompanhado de eficiente treinamento no reconhecimento do transtorno de humor bipolar nas mais diversas formas.

Kendrick ${ }^{4}$ aponta ainda três problemas nas recomendações das diretrizes: o diagnóstico não é fácil; muitos clínicos duvidam da eficácia dos antidepressivos em face de problemas sociais, apesar das evidências de que a resposta ao tratamento ocorre independentemente da causa aparente; e mesmo quando os médicos reconhecem a depressão e consideram o tratamento adequado, os pacientes com frequiência relutam em aceitá-lo, por acreditarem que a depressão se deve a eventos da vida e que os antidepressivos provocam dependência.

\section{Referências}

1. McIntyre JS. Usefulness and limitations of treatment guidelintes in psychiatry. World Psychiatry 2002;1:186-9.

2. Thompson C, Kinmonth AL, Stevens L, Peveler RC, Stevens A, Ostler $\mathrm{KJ}$, et al. Effects of a clinical-practice guideline and practeced-based education on detection and outcome of depression in primary care: Hampshire Depression Project randomized controlled trial. Lancet 2000;355:185-91.
O editorial de Kendrick ${ }^{4}$ gerou uma série de comentários enviados para o British Medical Journal, ${ }^{5}$ quase todos críticos ou contrários à sua opinião. Entretanto, ainda que se possa apresentar suporte ao uso de diretrizes destinadas ao clínico geral no tratamento da depressão, essas se baseiam em resultados após programas de treinamento mínimo.

Assim, seria desejável que o estabelecimento das diretrizes brasileiras para o tratamento da depressão, por iniciativa da AMB, seja seguido de avaliação do seu uso.

Irismar Reis de Oliveira Departamento de Neuropsiquiatria da Faculdade de Medicina da Universidade Federal da Bahia

Pedro Antônio Prado Lima

Grupo de Pesquisas em Neurobiologia do Comportamento, Instituto de Pesquisas Biomédicas, PUC-RS

3. Littlejohns P, Cluzeau F, Bale R, Grimshaw J, Feder G, Moran S. The quantity and quality of clinical practice guidelines for the management of depression in primary care in the UK. Br J Gen Pract 1999;49:205-10.

4. Kendrick T. Why can't GPs follow guidelines on depression? BMJ 2000;320:200-1.

5. Letters. Diagnosing and treating depression. BMJ 2000;320:1602-4. 